\title{
Effects of prior response-contingent reinforcement on superstitious behavior
}

\author{
GLORIA D. ELDRIDGE, JOSEPH J. PEAR, LAINE J. TORGRUD, and BLAIR H. EVERS \\ University of Manitoba, Winnipeg, Manitoba, Canada
}

\begin{abstract}
Three pigeons were exposed to fixed-time (FT) $15 \mathrm{sec}$, fixed-interval (FI) $15 \mathrm{sec}$ for performing an arbitrary response, a reversal back to FT $15 \mathrm{sec}$, and then extinction (no reinforcement). During each phase, a computer-controlled tracking system continuously recorded the position of the bird's head as it moved freely in the experimental chamber. During the first exposure to FT $15 \mathrm{sec}$, all 3 birds developed a pattern of feeder-wall-directed behavior with occasional circular excursions from the feeder immediately following reinforcement. During FI 15 sec, all birds performed the arbitrary operant, which consisted of contacting a virtual target sphere near the rear of the chamber, and did not engage in feederwall-directed behavior. During the reversal back to FT $15 \mathrm{sec}$, the birds developed a behavior sequence consisting of moving in the direction of the target sphere after reinforcement, followed by feeder-walldirected behavior prior to the next reinforcement. During extinction, either moves toward the target sphere or wall-directed behavior occurred separately, interspersed with reappearance of the two as a sequence, followed by cessation of both members of the behavior sequence. These findings indicate that prior reinforcement of an arbitrary response can affect the location and form of superstitious behavior that develope near the beginning of the interreinforcement interval, but that other factors (e.g., immediacy of reinforcement) affect the location and form of the behavior near the end of the interval. The findings can be interpreted in the context of superstitious chaining.
\end{abstract}

The effect of delivering reinforcement independent of behavior has received some attention in the operant literature. Since a reinforcer, by definition, strengthens any behavior it follows, Skinner (1948) argued that the effect of delivering reinforcement independent of behavior would be to increase the occurrence of any behavior that might be occurring at the time. If the next reinforcer was delivered when this behavior was occurring, the behavior should be strengthened further. In this way, the behavior could become predominant. In addition, Skinner described data obtained with pigeons that seemed to support this interpretation of the effect of response-independent reinforcement. Since the behavior that was conditioned did not produce the reinforcer, Skinner described the behavior as a superstition.

One strategy for studying superstition, or superstitious behavior, is to first condition a given response, using response-dependent reinforcement, and then change to response-independent reinforcement (e.g., Appel \& Hiss, 1962; Hermstein, 1966; Lachter, 1971; Lachter, Cole, \& Schoenfeld, 1971; Neuringer, 1970; Zeiler, 1968). For example, the experimental subject might first be exposed to a fixed-interval (FI) schedule, in which reinforcement is contingent on the first instance of the specified behavior that occurs after a fixed interval following the previous

This research was supported by Grant A7461 from the Natural Sciences and Engineering Research Council of Canada to J. J. Pear, and the study was conducted while G. D. Eldridge was supported by a Social Sciences and Humanities Research Council of Canada fellowship and L. J. Torgrud was supported by a Natural Sciences and Engineering Research Council of Canada fellowship. Reprints may be obtained from Joseph J. Pear, Department of Psychology, University of Manitoba, Winnipeg, MB R3T 2N2, Canada. reinforcement, and then to a fixed-time (FT) schedule in which reinforcement occurs at fixed intervals regardless of the occurrence of the behavior. The typical finding has been that the behavior strengthened under responsedependent reinforcement is maintained, although at a reduced level, under response-independent reinforcement. This finding has been taken as supporting Skinner's interpretation of the effect of response-independent reinforcement.

However, more direct replications of Skinner's (1948) study have been interpreted as not supporting Skinner's concept of superstition. Most notably, Staddon and Simmelhag (1971) and Timberlake and Lucas (1985) presented food to pigeons on an FT 15-sec schedule, and found that stereotypic responses occurred near the ends of the interreinforcement intervals. However, these stereotypic responses were highly similar across the birds in each study, suggesting that these responses were elicited rather than reinforced. The stereotypic responses that developed near the ends of the intervals differed in the two studies, perhaps due to different behavioral histories, species differences, or the different lengths of exposure to the FT schedule. In Staddon and Simmelhag's study, the stereotypic response was pecking, whereas in Timberlake and Lucas's study, it consisted of feeder-wall-directed behavior. Furthermore, the two studies differed in terms of the behavior that occurred immediately after reinforcement. Staddon and Simmelhag reported that their birds engaged in idiosyncratic patterns after reinforcement, whereas Timberlake and Lucas reported that their birds usually made circular movements away from the feeder. In both studies, the authors suggested that the behavior that occurred after reinforcement, termed interim be- 
havior, was not superstitious (as defined above). Staddon and Simmelhag argued that the interim behavior was not superstitious because it was not temporally contiguous with reinforcement. Timberlake and Lucas suggested that the interim behavior they obtained (circling) was an elicited component of the birds' species-specific feeding pattern.

In one of the experiments in their study, Timberlake and Lucas (1985, Experiment 2) tested whether responseindependent reinforcement would maintain behavior conditioned with response-dependent reinforcement. They shaped two high-probability responses (turning or pecking) in different birds, reinforced the responses on an FI 15-sec schedule, and then changed the contingency to FT $15 \mathrm{sec}$. Pecking declined rapidly to or near zero on the FT 15-sec schedule and feeder-wall-directed behavior increased for the 2 birds that had been conditioned to peck. Turning also decreased, although not to zero, and feederwall-directed behavior did not increase for the 2 birds that had been conditioned to turn. The absence of a baseline of response-independent reinforcement prior to shaping the turning response made it difficult to determine whether, and to what extent, prior reinforcement of that response affected the behavior that was maintained under the subsequent FT 15 -sec schedule.

The purpose of the present study was to obtain further information concerning the effects of prior responsedependent reinforcement on behavior subsequently maintained by response-independent reinforcement. The study differed from previous studies in that (1) a continuous three-dimensional tracking system was used, which permitted an accurate representation over time of the position of a pigeon in the experimental chamber; (2) an extensive baseline was obtained with response-independent reinforcement prior to the conditioning of a new response; and (3) the new response that was conditioned was a lowprobability response, as indicated by its lack of occurrence during no-reinforcement and response-independentreinforcement baselines. The major question of interest was whether this previously conditioned response could be maintained by response-independent reinforcement, or whether it would be supplanted by behavior with a higher initial probability.

\section{METHOD}

\section{Subjects}

Three experimentally naive male pigeons were obtained from Vancouver Island Mountain Squab. Two Texas Pioneers (a White Carneau/Silver King crossbreed; Bird I and Bird 2) were maintained at approximately $80 \%$ of their free-feeding weights; 1 White King (Bird 3) was maintained at approximately $90 \%$. In order for the apparatus to track the movements of the birds, their heads and necks were blackened with shoe polish prior to each session. The birds were housed in individual cages in a colony room regulated by a 12-h-on:12-h-off light:dark cycle. Water was freely available in their home cages.

\section{Apparatus}

The apparatus recorded the position of the bird's head every $1 / 30$ th sec as the bird moved freely in the experimental chamber.
A description of the apparatus has been published elsewhere (Pear \& Eldridge, 1984). The inner dimensions of the experimental chamber were $57 \times 57 \times 38 \mathrm{~cm}$. Two walls of the chamber consisted of clear glass, one wall consisted of white opaque Plexiglas, one wall consisted of white opaque Plexiglas and metal painted white, and the lid was clear Plexiglas. Located near the center of the opaque Plexiglas and metal "front" wall was a circular food aperture into which an electronically operated food hopper, containing commercial poultry food, could be raised for reinforcement. The feeder aperture was illuminated continuously by two SL-313 bulbs in series with a 3,352- $\Omega$ resistor, except during feeder presentations when the resistor was isolated from the circuit. Thus, the intensity of the illumination increased during feeder presentations. Each food presentation lasted $5 \mathrm{sec}$. Since this experiment did not involve keypecking as a response, a response key located on the front wall $26 \mathrm{~cm}$ from the aluminum mesh floor and $21 \mathrm{~cm}$ from the left wall was covered by an opaque white shield. A "feedback" relay behind the key could be progammed to provide a click contingent on a response.

The chamber was illuminated through the transparent sides and lit by light from four banks of fluorescent ceiling lights in the experimental room. These lights were relay-controlled and turned on automatically at the beginning of the session and off at the end. Ventilation was provided by air spaces in the top and bottom of the chamber. The chamber was in a room separate from the one containing the programming and recording equipment. A speaker and white-noise generator provided a constant masking noise in the room. Room ventilation was through a ceiling register.

Two TV cameras connected to a video-acquisition module were oriented perpendicularly to the two adjacent glass walls. Each bird's head was painted with black shoe polish such that the head was the only dark region in the chamber. The video-acquisition module scanned down the image from each camera every $1 / 30$ th sec until it encountered a dark region of a critical width, and computed the three spatial coordinates of the point at the center of this region. This point was defined as the position of the pigeon's head. The chamber was turned at an angle of $10^{\circ}$ to the cameras to prevent interference from the aluminum frame of the chamber, excluding from view narrow segments on the right front and two side walls of the chamber. Because of a memory limitation, the computer was unable to store data from another narrow segment on the left front wall. The video-acquisition module was connected to a Cromemco Z-2D microcomputer that stored the position data for later analysis. Data were averaged over three blocks, yielding 10 data points per second. The microcomputer also controlled experimental sessions. An Epson dot-matrix printer was used for graphing the data. Both cameras were connected to a television monitor in the room containing the programming equipment, and a selector switch permitted visual observation from either camera throughout each session. For a block diagram of the system, see Pear and Eldridge (1984, Figure 1, p. 461).

\section{Procedure}

General experimental procedures. Sessions were conducted 5 days per week at approximately the same time each day. Each session was terminated after 60 reinforcers or $3,600 \mathrm{sec}$, whichever occurred first. Reinforcer presentation time was excluded from calculations of session time, from the schedule of reinforcement, and from all data analyses.

Preliminary training. The birds were magazine trained by being placed in the chamber with the food hopper raised and the feeder aperture brightly illuminated. Once the bird had approached the raised hopper and consumed grain for approximately $20 \mathrm{sec}$, the hopper was repeatedly raised and lowered at varying intervals independently of the bird's behavior. This continued until the bird approached and consumed food within $3 \mathrm{sec}$ for 10 consecutive trials. The feeder light was bright only when the hopper was raised; at all other times it was dim. 
Table 1

Number of Sessions in Each Phase

\begin{tabular}{lccc}
\hline Phase & Bird 1 & Bird 2 & Bird 3 \\
\hline FT 15 sec & 10 & 13 & 10 \\
FI 15 sec & 19 & 40 & 13 \\
FT 15 sec & 20 & 33 & 27 \\
EXT & 3 & 6 & 7 \\
\hline
\end{tabular}

Experimental design. After magazine training, the birds were given a baseline session of 3,600 sec during which no reinforcement was presented. They were then exposed to the following four phases: (1) FT $15 \mathrm{sec}$, (2) reinforcement of a head-raising response in a specific location of the chamber on FI $15 \mathrm{sec}$, (3) return to FT $15 \mathrm{sec}$, and (4) extinction (no reinforcement). The number of sessions for each bird in each phase is shown in Table 1 .

The target response that was selected for FI $15 \mathrm{sec}$ was one that none of the birds had been observed to make during baseline or during the first phase of FT $15 \mathrm{sec}$. The computer program defined a virtual target sphere, $3 \mathrm{~cm}$ in diameter, with its center located $13.5 \mathrm{~cm}$ from the left wall, $21 \mathrm{~cm}$ from the back wall, and $32 \mathrm{~cm}$ from the aluminum mesh floor of the chamber. Because this was slightly above the usual standing heights of the birds, each bird could "contact" the target only by raising its head. Each contact of the bird's head with the target sphere during all phases was programmed to be followed by a click from the feedback relay. After the first FT phase and prior to the FI phase, contact with the virtual target sphere was shaped using the procedure described by Pear and Legris (1987), in which the apparatus automatically reinforced successive approximations to the target response. Shaping took three sessions for Bird 1, three sessions for Bird 2, and four sessions for Bird 3. Following shaping, the birds were exposed to gradually increasing FI values until FI $15 \mathrm{sec}$ was reached. This was accomplished in 4 sessions for Bird 1, 26 sessions (including 5 sessions of reshaping) for Bird 2, and 7 sessions for Bird 3.

\section{RESULTS}

Figure 1 presents within-session data plotted as distance from the feeder over time for the last session of FT $15 \mathrm{sec}$, the last session of FI $15 \mathrm{sec}$, and the last session of the reversal to FT $15 \mathrm{sec}$ for each bird. Absolute distance from the feeder is indicated on the vertical axis of the figure, and session time is shown on the horizontal axis. Reinforcer presentations are indicated in the lower band at the bottom of each graph. Note that the graphs in the top row show that during the first FT 15-sec phase, all 3 birds exhibited repetitive movement in the general vicinity of the feeder. Visual observation revealed this behavior to be similar to the back-and-forth feeder-walldirected behavior described by Timberlake and Lucas (1985). The graphs in the middle row show that during
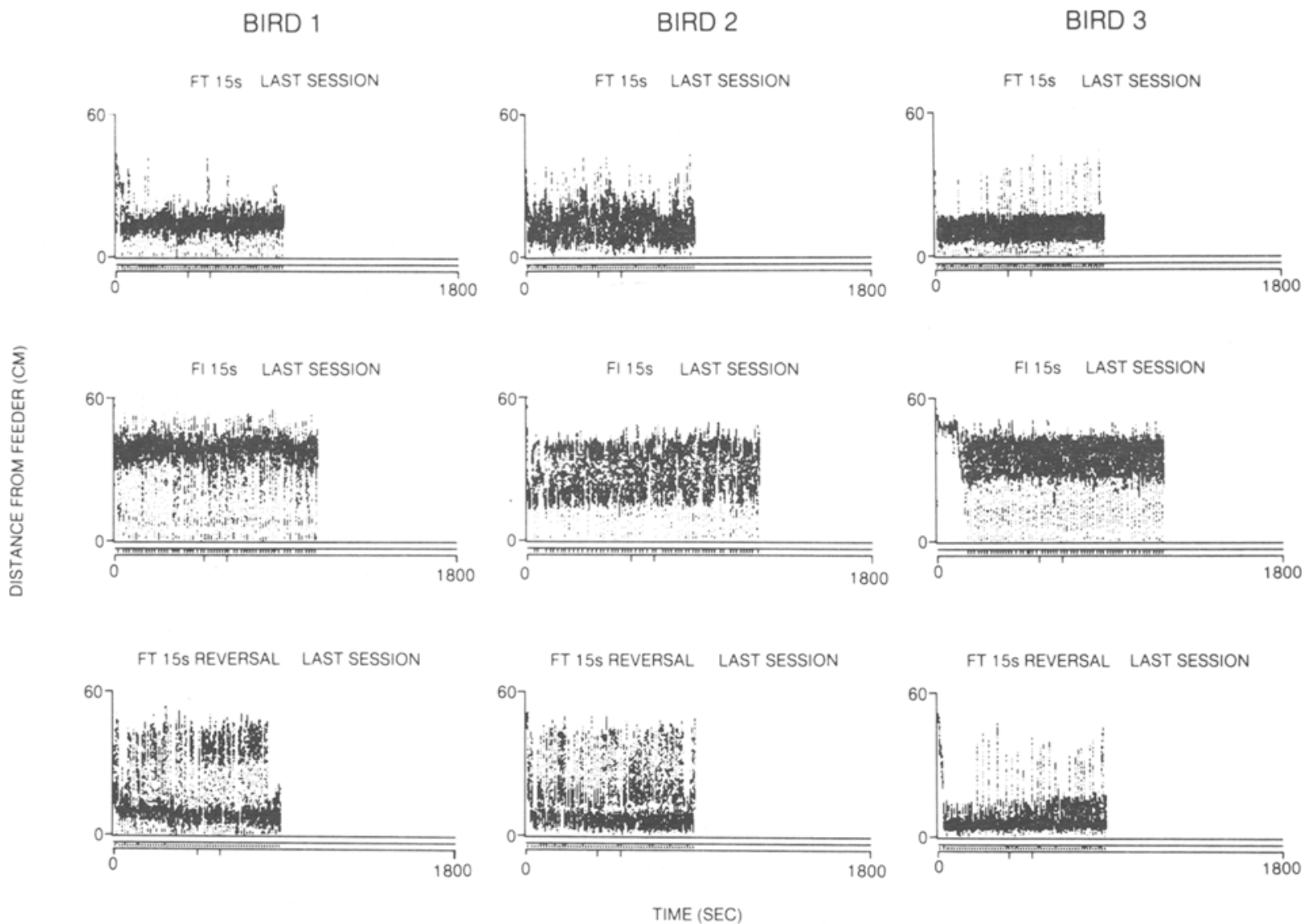

Figure 1. Distance from feeder over time for the last session of FT $15 \mathrm{sec}$, the last session of FI 15 sec, and the last session of the reversal to FT 15 sec for each bird. Absolute distance from the feeder is indicated on the vertical axis; session time is shown on the horizontal axis. Reinforcer presentations are indicated in the lower band at the bottom of each graph. 
the FI 15-sec phase, activity was shifted away from the feeder. This was because the bird was contacting the target sphere, as specified by the reinforcement contingency. The graphs in the bottom row show that the behavior had reversed only partially by the last session of the reversal to FT $15 \mathrm{sec}$. Birds 1 and 2 continued to make long excursions from the feeder such as had occurred during FI $15 \mathrm{sec}$ but not during the first exposure to FT $15 \mathrm{sec}$. However, all 3 birds clearly showed repetitive movement in the general vicinity of the feeder as they had during the first exposure to FT $15 \mathrm{sec}$. Visual observation revealed that this was essentially the same feeder-walldirected behavior that had occurred during the first exposure to FT $15 \mathrm{sec}$, and that the excursions and the feeder-wall-directed behavior occurred in a reliable sequence within each reinforcement interval (see below).

To provide a more detailed comparison between the behavior patterns during the last sessions of FT $15 \mathrm{sec}$, FI $15 \mathrm{sec}$, and the reversal to FT $15 \mathrm{sec}$, Figure 2 shows expansions of 120 -sec segments from approximately the middle of the graphs in Figure 1, indicated by cursors at the bottoms of the graphs in Figure 1. Note that the graphs in the top row of Figure 2 clearly show the repetitive movements in the general vicinity of the feeder exhibited by all 3 birds during the first exposure to FT $15 \mathrm{sec}$. In addition, these graphs show occasional excursions from the feeder after reinforcement during the first exposure to FT $15 \mathrm{sec}$. The graphs in the middle row again show that the activity was shifted away from the feeder as a result of the FI 15-sec schedule. In addition, these graphs show that each bird immediately left the vicinity of the feeder after each reinforcement. The graphs in the bottom row for Birds 1 and 2 show that at the end of the reversal to FT $15 \mathrm{sec}$, these birds made longer and more consistent excursions from the feeder following reinforcement than they did at the end of the initial exposure to FT $15 \mathrm{sec}$. After each excursion, both birds returned to the vicinity of the feeder several seconds prior to the next reinforcement. This constituted the previously mentioned reliable sequence of excursions and feeder-wall-directed behavior that occurred for these 2 birds within each reinforcement interval. There is some indication in Figure 2 that Bird 3 also more frequently made excursions from the feeder following reinforcement at the end of the second exposure to FT $15 \mathrm{sec}$ than it had at the end of the first exposure to FT $15 \mathrm{sec}$, although these excursions were less consistent and shorter (both in time and in distance) than for those of the other birds. After each excursion, it too returned to the vicinity of the feeder several seconds prior to the next reinforcement, and was observed
BIRD 1

FT 15S LAST SESSION
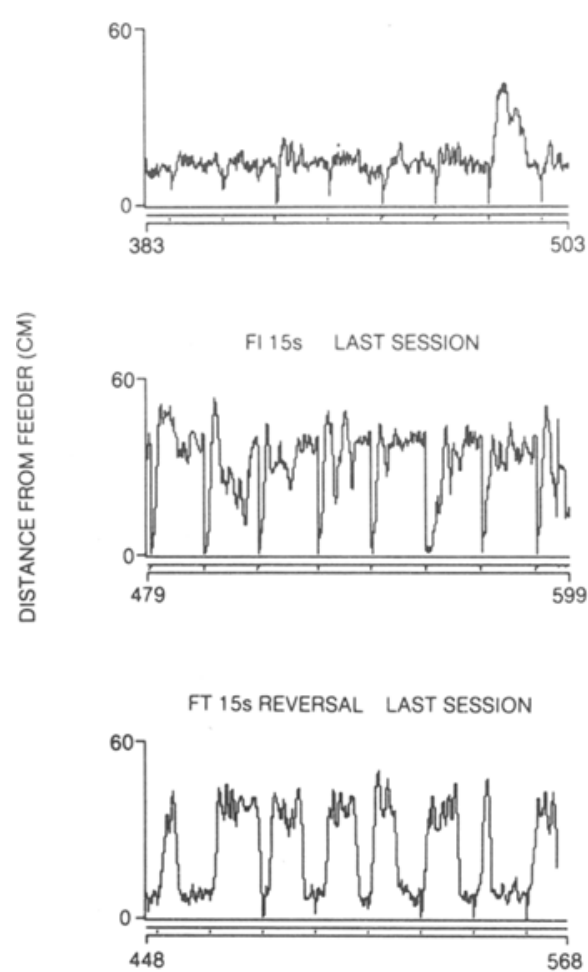

BIRD 2

FT 15S LAST SESSION

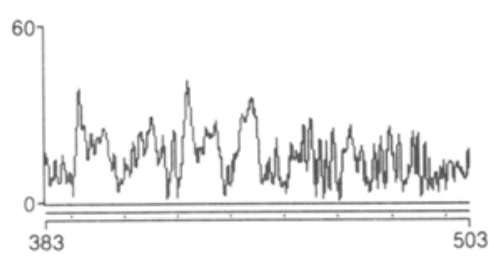

FI 15 S LAST SESSION

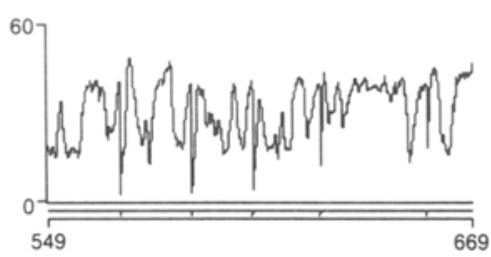

FT 15s REVERSAL LAST SESSION

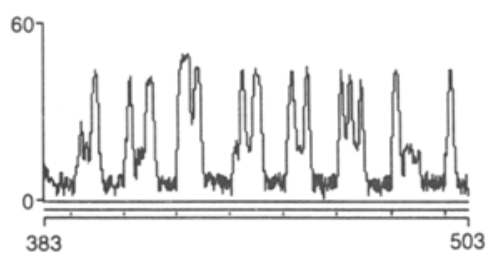

BIRD 3

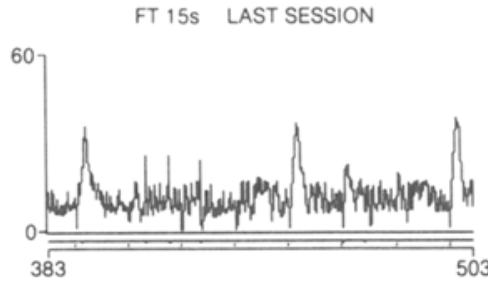

FI 15S LAST SESSION

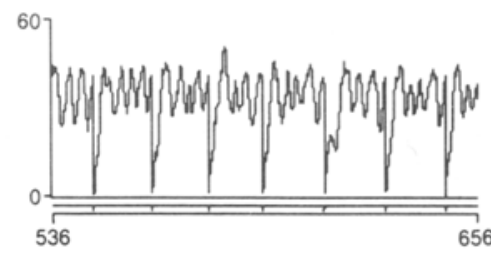

FT 15s REVERSAL LAST SESSION

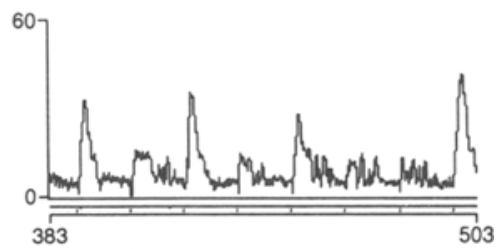

TIME (SEC)

Figure 2. Expansions of the $120-\mathrm{sec}$ segments indicated by the cursors at the bottom of the graphs in Figure 1. (See Figure 1 for explanation.) 
to exhibit feeder-wall-directed behavior. However, the interreinforcement behavior sequence shown by the other birds was not shown as consistently by this bird.

Figure 3 shows the data plotted from an overhead perspective for the portions of the sessions shown in Figure 2. The positions of the feeder and the virtual target sphere are indicated by the top and lower black circles, respectively; the dashed lines indicate regions of the chamber from which data could not be obtained for technical reasons. Since each point in the overhead plot indicates the average position of the bird in a particular $0.1-\mathrm{sec}$ inter$\mathrm{val}$, the density of the dark areas provides an indication of the proportion of time spent in various parts of the chamber. Note that, as already seen, all birds usually remained close to the feeder during the first exposure to FT $15 \mathrm{sec}$. During the exposure to FI $15 \mathrm{sec}$, the birds were consistently in the vicinity of the target sphere between reinforcements. During the second exposure to FT $15 \mathrm{sec}$, in addition to movement toward the feeder, all birds showed a clear tendency to move toward the target sphere. This tendency, which was evident for all birds, was not present during the initial exposure to FT $15 \mathrm{sec}$.
Note that because the distance graphs shown in the previous figures did not reflect direction, they did not indicate the change in the direction of the excursions that occurred in Bird 3 as a result of its exposure to the FI 15 -sec schedule.

Figure 4 gives an indication of the developmental process involved in the formation of the behavior sequence that appeared during the return to FT $15 \mathrm{sec}$. For each bird, distance graphs from several early sessions and one or two later sessions of the return to FT $15 \mathrm{sec}$ were chosen for presentation. Note that for Bird 1, the pattern developed under FI $15 \mathrm{sec}$ (see Figure 1) continued until early in the third session of the return to FT $15 \mathrm{sec}$, and then rather abruptly changed to the pattern developed during the first exposure to FT $15 \mathrm{sec}$. During subsequent sessions, the patterns alternated, as indicated in the graphs for Sessions 4 and 5. By Session 10, the final pattern shown in Figure 1 had developed. Birds 2 and 3 followed a similar developmental pattern. For Bird 2, the abrupt return of the pattern shown during the initial exposure to FT $15 \mathrm{sec}$ occurred early in Session 2. For Bird 3, the abrupt change occurred at the beginning of Session 2 . This
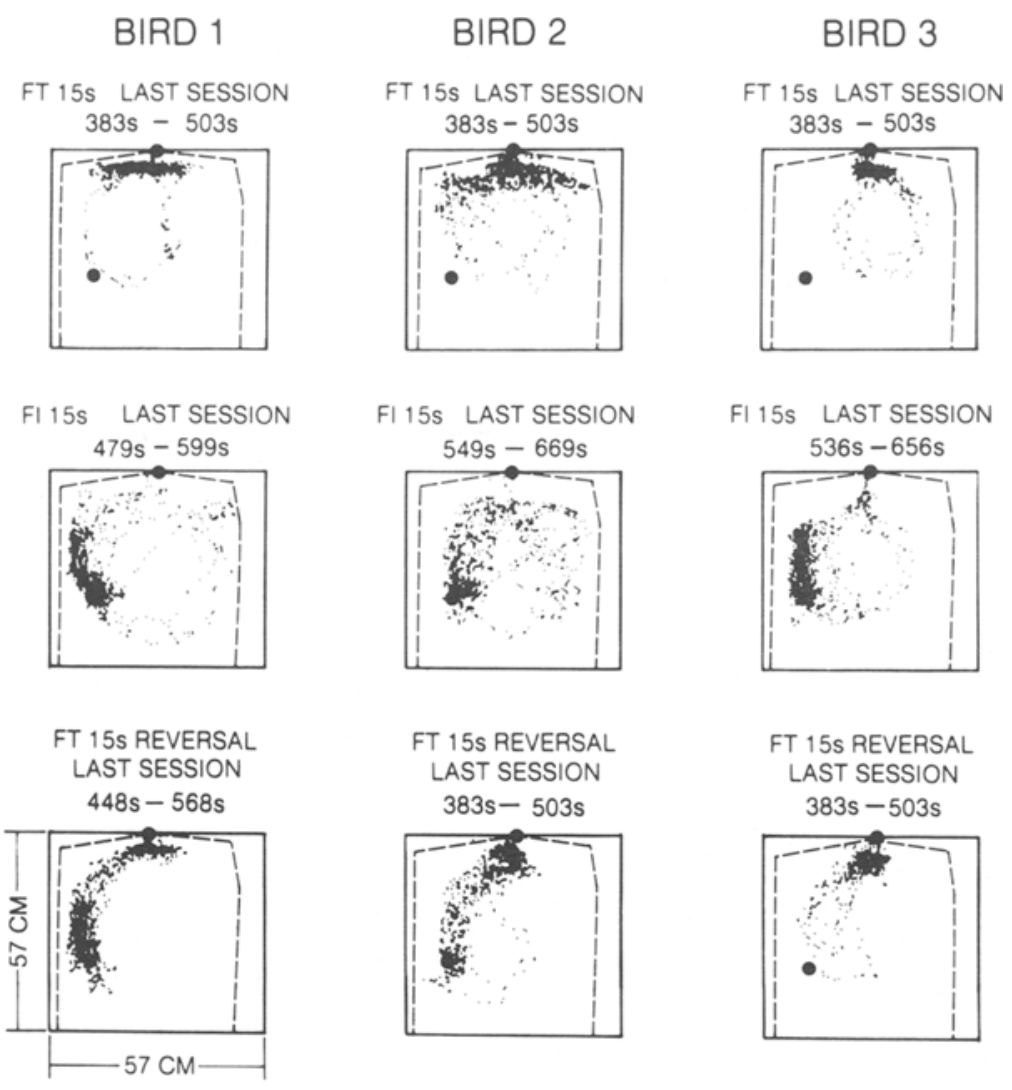

TIME (SEC)

Figure 3. Data plotted from an overhead perspective for the 120-sec segments shown in Figure 2. The top and lower black circles indicate the positions of the feeder and the target sphere, respectively. The dashed lines indicate regions of the experimental chamber from which data could not be obtained for technical reasons, as explained in the apparatus section. 

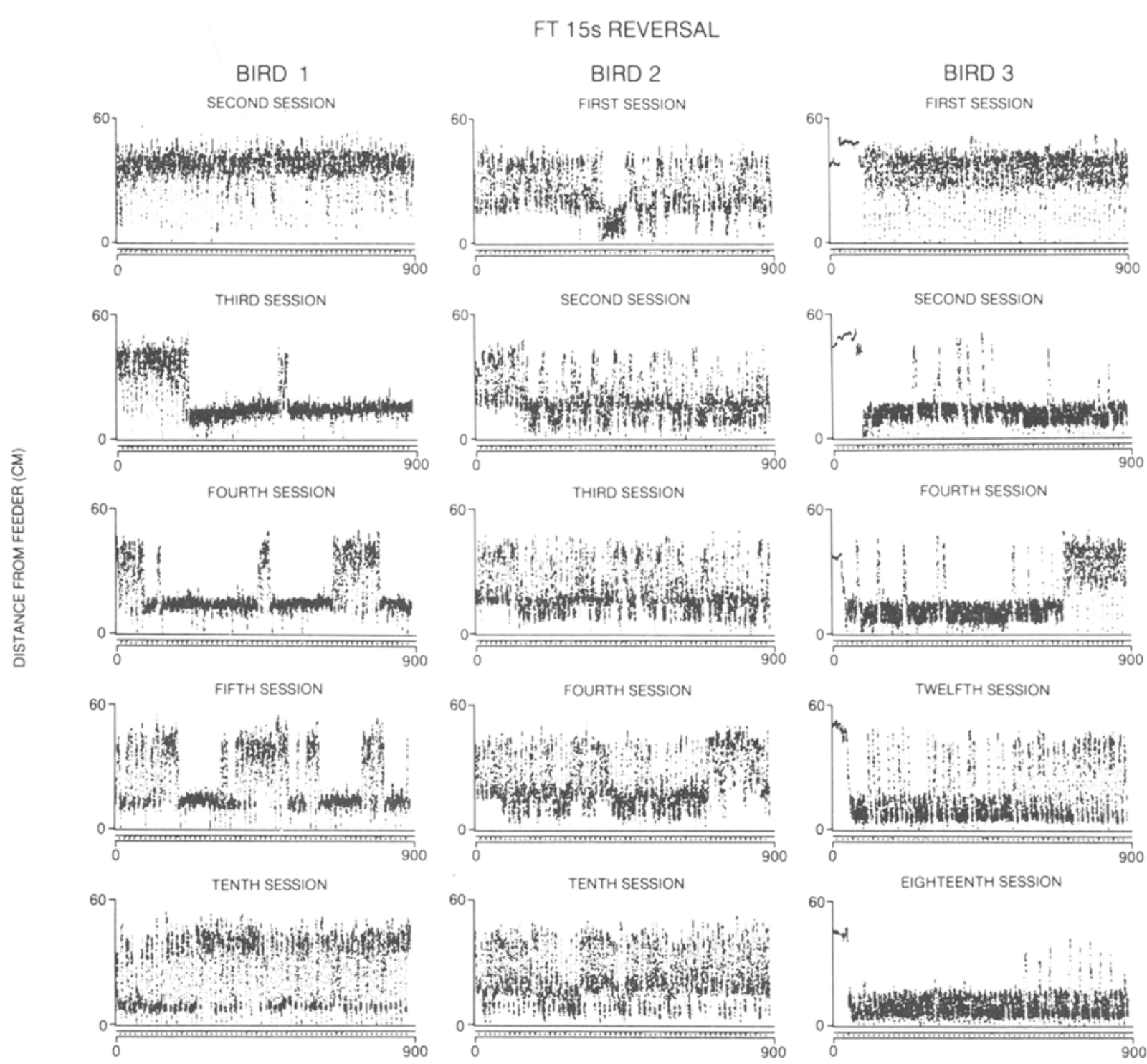

TIME (SEC)

Figure 4. Distance graphs from selected sessions, indicating the development of the behavior sequence that appeared during the reversal to FT 15 sec. See Figure 1 for explanation.

bird differed from the other two in that the pattern that had developed during FI $15 \mathrm{sec}$ had virtually disappeared by Session 18 of the return to FT $15 \mathrm{sec}$. Over the next nine sessions, however, the behavior recovered moderately (see Figure 1).

Figure 5 shows the distance data over the first (top row) and second (bottom row) halves of the first extinction session for each bird. Both the behavior developed during the first exposure to FT $15 \mathrm{sec}$ and the behavior developed during FI $15 \mathrm{sec}$ occurred during this session for all 3 birds. Visual observation revealed that, in addition to engaging in activity in the vicinity of the feeder, all birds showed a resurgence (Epstein, 1985) of activity in the vicinity of the target sphere. Over the following ses- sions of extinction (not shown), both behaviors were replaced with general inactivity.

\section{DISCUSSION}

The first exposure to the FT 15-sec schedule in the present study resulted in feeder-wall-directed behavior, in which the birds engaged in repetitive movements near the feeder wall. This behavior returned in what appeared to be close to its original form during the reintroduction of the FT 15-sec schedule after reinforcement of an arbitrary response on FI $15 \mathrm{sec}$ and alternated with the behavior established during the FI schedule (i.e., contacting the virtual target sphere). Of particular interest is the 


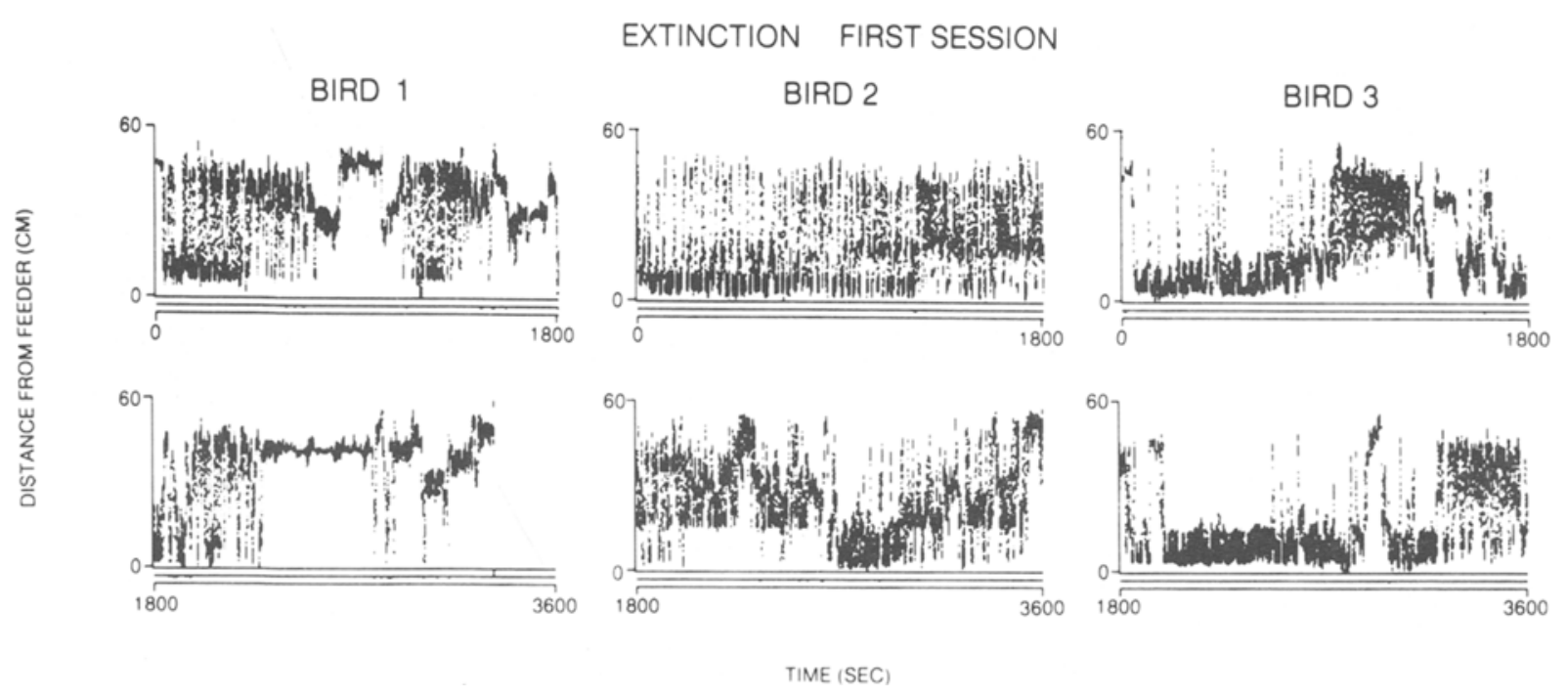

Figure 5. Distance graphs for the first and second $1,800 \mathrm{sec}$ of the first extinction session. See Figure 1 for explanation.

temporal sequencing that eventually developed during the final sessions of the second exposure to FT $15 \mathrm{sec}$ : all birds usually moved toward the target sphere immediately following reinforcement and engaged in feeder-walldirected behavior just prior to the next reinforcement. This sequence was especially consistent for Birds 1 and 2 . Thus it appears that the effect of reinforcing a specific arbitrary response was to alter the form of the behavior immediately after reinforcement on an FT 15 -sec schedule. The results obtained in the present study are similar to those obtained by Timberlake and Lucas (1985, Experiment 2) with the 2 birds that were trained to turn on an FI 15 -sec schedule. Although there was no baseline in Timberlake and Lucas's experiment, comparisons of the data of those birds with the data of other birds in their study (e.g., compare their Figures 2, 3, 4, and 5) indicate that some of the previously conditioned behavior may have persisted during response-independent reinforcement. Moreover, although there is ambiguity in their data presentation regarding this point, the previously conditioned behavior seems to have occurred more frequently immediately after reinforcement (see their Figure 5). Despite these difficulties, our data seem compatible with the data produced by the birds in which locomotor behavior was conditioned in Timberlake and Lucas's study. It is not clear why the results differed for the birds in which pecking was conditioned.

It is possible to interpret the data of the present study and those of Timberlake and Lucas (1985, Experiment 2) within the context of superstition. Note that, although not deliberately programmed, there was an explicit reinforcement contingency for being close to the feeder wall at the time of food delivery: (1) reinforcement was more immediate, and (2) more food could be obtained because the feeder was available for a limited time during each reinforcement. Either or both of these factors would seem to impose some constraint on the location of the behavior that would be likely to develop just prior to reinforcement. No such constraint would exist for behavior occurring after reinforcement, and its form and location would therefore be more susceptible to a prior reinforcement history. Although behavior occurring early in the interval is not immediately followed by reinforcement, immediacy is not always necessary to maintain behavior. For example, behavior in an early link of a behavior chain is maintained by the reinforcement that occurs contingent on the behavior in the last link (Kelleher \& Gollub, 1962). In addition, as Catania and Cutts (1963) have shown, a response may be maintained adventitiously by reinforcement that follows a subsequent response. Catania and Cutts used the term concurrent superstition to describe behavior maintained by this sort of adventitious reinforcement, and the resulting behavior sequence bears some resemblance to a behavior chain. Thus, a possible interpretation of the persistence of the previously conditioned locomotor behavior during response-independent reinforcement in the present study is that this behavior was a concurrent superstition maintained by the reinforcement following feederwall-directed behavior, which tended to occur prior to feeder presentations because it was more immediately reinforced.

There are two aspects of the data in the present experiment that seem consistent with this interpretation. One concerns the manner in which the behavior sequence developed during the second exposure to FT $15 \mathrm{sec}$. As indicated in Figure 4, the two components of the sequence were both present and alternating for a number of sessions prior to the formation of the sequence. This is similar to the gradual decrease in "out-of-sequence behavior" that has been observed during acquisition of a twocomponent chain (i.e., reinforcement contingent on the completion of both components sequentially) in which the 
members were first conditioned separately (D'Andrea, 1969). The other aspect of the data that is consistent with this interpretation is the effect of extinction. As indicated by Figure 5 , the entire sequence occurred at the beginning of extinction for all 3 birds. Then either moves toward the target sphere or wall-directed behavior $o c$ curred separately, interspersed with reappearances of the two as a sequence. The two members of the behavior sequence ceased altogether in the first extinction session for Bird 1 and in later extinction sessions (which are not shown in the figure) for the other 2 birds. Thus, the manner in which the behavior sequence in the present study decreased is similar to the way in which a behavior chain may break down into its components prior to the elimination of those components during extinction (D'Andrea, 1969; Laties, Weiss, Clark, \& Reynolds, 1965; Skinner, 1938, pp. 103-106).

\section{REFERENCES}

APPEL, J. B., Hiss, R. H. (1962). The discrimination of contingent from noncontingent reinforcement. Joumal of Comparative \& Physiological Psychology, 55, 37-39.

Catania, A. C., Cutrs, D. (1963). Experimental control of superstitious responding in humans. Journal of the Experimental Analysis of Behavior, 6, 203-208.

D'ANDREA, T. (1969). Extinction of a heterogeneous chain after several reinforcement schedules. Journal of the Experimental Analysis of Behavior, 12, 127-135.

EpsteIn, R. (1985). Extinction-induced resurgence: Preliminary investigations and possible applications. Psychological Record, 35, 143-153.

HerRnstein, R. J. (1966). Superstition: A corollary of the principles of operant conditioning. In W. K. Honig (Ed.), Operant behavior: Areas of research and application (pp. 33-51). New York: AppletonCentury-Crofts.
Kelleher, R. T., Gollub, L. R. (1962). A review of positive conditioned reinforcement. Joumal of the Experimental Analysis of Behavior, 5, 543-597.

LACHTER, G. D. (1971). Some temporal parameters of non-contingent reinforcement. Joumal of the Experimental Analysis of Behavior, 16, 207-217.

Lachter, G. D., Cole, B. K., Schoenfeld, W. N. (1971). Response rate under varying frequency of non-contingent reinforcement. Journal of the Experimental Analysis of Behavior, 15, 233-236.

Laties, V. G., Weiss, B., ClakK, R. L., Reynolds, M. D. (1965). Overt "mediating" behavior during temporally spaced responding. Journal of the Experimental Analysis of Behavior, 8, 107-116.

Neuringer, A. J. (1970). Superstitious key pecking after three peckproduced reinforcements. Joumal of the Experimental Analysis of Behavior, 13, 127-134.

Pear, J. J., Eldridge, G. D. (1984). The operant-respondent distinction: Future directions. Joumal of the Experimental Analysis of Behavior, 42, 453-467.

Pear, J. J., Le Legris, J. A. (1987). Shaping by automated tracking of an arbitrary operant response. Joumal of the Experimental Analysis of Behavior, 47, 241-247.

SkINNER, B. F. (1938). The behavior of organisms: An experimental analysis. New York: Appleton-Century-Crofts.

SkINNER, B. F. (1948). "Superstition" in the pigeon. Joumal of Experimental Psychology, 38, 168-172.

Staddon, J. E. R., \& Simmelhag, V. L. (1971). The "superstition" experiment: A reexamination of its implications for the principles of adaptive behavior. Psychological Review, 78, 3-43.

Timberlake, W., LuCAs, G. A. (1985). The basis of superstitious behavior: Chance contingency, stimulus substitution, or appetitive behavior? Joumal of the Experimental Analysis of Behavior, 44, 279-299.

ZEILER, M. D. (1968). Fixed and variable schedules of responseindependent reinforcement. Joumal of the Experimental Analysis of Behavior, 11, 405-414.

(Manuscript received August 28, 1987; revision accepted for publication January 28,1988 .) 